\title{
Long Bone Epiphysis
}

National Cancer Institute

\section{Source}

National Cancer Institute. Long Bone Epiphysis. NCI Thesaurus. Code C52722.

The rounded proximal and distal ends of a long bone, which contains mostly spongy bone and develops from secondary ossification centers. 